\title{
On Understanding Ageing: Design and Inferences
}

\section{Introduction}

In a recent issue of Gerontology, Scott Hofer and Martin Sliwinski [1] presented a stimulating paper evaluating research designs for age-related changes. In their original paper they raised a number of issues concerning the utility of cross-sectional and longitudinal designs. In particular, they outlined some potential problems in accurately identifying shared age-related variance that may arise due to population average changes with age on cross-sectional estimates. They proposed a novel narrow age cohort (NAC) design to address some of the interpretative problems arising from more traditional designs.

Their paper [1] was sent to other scholars who are currently seeking to identify age-related changes, primarily in the realm of cognition. They were invited to comment on the Hofer and Sliwinski paper. The commentators highlight the types of research questions for which the limitations are likely to be most important, question some of the assertions about longitudinal designs and assumptions required by the NAC design, identify other confounding variables that threaten narrow cohort designs, and provide illustrations of further paradigms and models for understanding age-related changes. In this issue, the collection of the commentaries is presented, together with a rejoinder from Hofer and coworkers in which they flesh out their original thesis and respond to the points raised by the commentators.

The collection canvasses a range of ways in which traditional and the proposed design may bias or enhance interpretation of study findings. Taken together, the authors provide a unique window on cutting edge statistical and design issues, as well as some of the conceptual dilemmas that confront gerontological researchers. On the one hand, they provide a sobering perspective on the limitations of our research tools for answering questions at the core of understanding ageing. On the other hand, they offer constructive options and strategies for pursuing research questions with expertise. I commend them to you as a rare and rich resource of technical and conceptual wisdom invaluable to all those seeking to understand ageing.

Mary Luszcz, Adelaide

\begin{tabular}{ll}
\hline KARGER & ( 2002 S. Karger AG, Basel \\
Fax +4161306 1234 & \\
$\begin{array}{l}\text { E-Mail karger@karger.ch } \\
\text { www.karger.com }\end{array}$ & $\begin{array}{l}\text { Accessible online at: } \\
\text { www.karger.com/journals/ger }\end{array}$
\end{tabular}

